\title{
Using machine-learning risk prediction models to triage the acuity of undifferentiated patients entering the emergency care system: a systematic review
}

Jamie Miles $^{1 *} \mathbb{D}$, Janette Turner $^{2}$, Richard Jacques ${ }^{2}$, Julia Williams ${ }^{3}$ and Suzanne Mason ${ }^{2}$

\begin{abstract}
Background: The primary objective of this review is to assess the accuracy of machine learning methods in their application of triaging the acuity of patients presenting in the Emergency Care System (ECS). The population are patients that have contacted the ambulance service or turned up at the Emergency Department. The index test is a machine-learning algorithm that aims to stratify the acuity of incoming patients at initial triage. This is in comparison to either an existing decision support tool, clinical opinion or in the absence of these, no comparator. The outcome of this review is the calibration, discrimination and classification statistics.

Methods: Only derivation studies (with or without internal validation) were included. MEDLINE, CINAHL, PubMed and the grey literature were searched on the 14th December 2019. Risk of bias was assessed using the PROBAST tool and data was extracted using the CHARMS checklist. Discrimination (C-statistic) was a commonly reported model performance measure and therefore these statistics were represented as a range within each machine learning method. The majority of studies had poorly reported outcomes and thus a narrative synthesis of results was performed.

Results: There was a total of 92 models (from 25 studies) included in the review. There were two main triage outcomes: hospitalisation ( 56 models), and critical care need (25 models). For hospitalisation, neural networks and tree-based methods both had a median C-statistic of 0.81 (IQR 0.80-0.84, 0.79-0.82). Logistic regression had a median C-statistic of 0.80 (0.74-0.83). For critical care need, neural networks had a median C-statistic of 0.89 (0.86-0.91), tree based 0.85 (0.84$0.88)$, and logistic regression $0.83(0.79-0.84)$.

Conclusions: Machine-learning methods appear accurate in triaging undifferentiated patients entering the Emergency Care System. There was no clear benefit of using one technique over another; however, models derived by logistic regression were more transparent in reporting model performance. Future studies should adhere to reporting guidelines and use these at the protocol design stage.

(Continued on next page)
\end{abstract}

\footnotetext{
*Correspondence: Jamie.miles@nhs.net; j.miles@sheffield.ac.uk

${ }^{1}$ Yorkshire Ambulance Service, Brindley Way, Wakefield WF2 OXQ, UK

Full list of author information is available at the end of the article
}

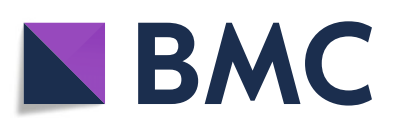

(c) The Author(s). 2020 Open Access This article is licensed under a Creative Commons Attribution 4.0 International License, which permits use, sharing, adaptation, distribution and reproduction in any medium or format, as long as you give appropriate credit to the original author(s) and the source, provide a link to the Creative Commons licence, and indicate if changes were made. The images or other third party material in this article are included in the article's Creative Commons licence, unless indicated otherwise in a credit line to the material. If material is not included in the article's Creative Commons licence and your intended use is not permitted by statutory regulation or exceeds the permitted use, you will need to obtain permission directly from the copyright holder. To view a copy of this licence, visit http://creativecommons.org/licenses/by/4.0/. 
(Continued from previous page)

Registration and funding: This systematic review is registered on the International prospective register of systematic reviews (PROSPERO) and can be accessed online at the following URL: https://www.crd.york.ac.uk/PROSPERO/display_ record.php?|D=CRD42020168696

This study was funded by the NIHR as part of a Clinical Doctoral Research Fellowship.

Keywords: Ambulance service, Emergency department, Machine learning, Triage, Patients

\section{Introduction}

Rationale

Machine learning (ML) can be defined as 'a set of methods that can automatically detect patterns in data, and then use uncovered patterns to predict future data, or to perform other kinds of decision making under uncertainty' [1]. To date, ML has already proven effective at predicting outcomes for disease specific patients such as predicting bronchiolitis in infants and predicting whether trauma patients require a computerised tomography scan (CT) or have a cranio-cervical junction injury [2-4]. Other models have outperformed existing tools such as the Global Registry of Acute coronary Events (GRACE) and Thrombolysis In Myocardial Infarction (TIMI) risk tools at predicting cardiovascular risk $[5,6]$.

Initial triage at any stage of the Emergency Care System (ECS) has become challenging due to the increase in patients with varying levels of acuity [7]. Patients in a modern ECS have complex needs, which can often span mental health and social care [8].

Recently, there has been increased interest in combining 'artificial intelligence' with the Emergency Department for the purpose of initial triage [9-12]. However, this has been largely through the use of supervised learning algorithms, a sub-category of ML techniques [9]. The benefit of using these ML methods is they can identify non-linear relationships between candidate predictors and the outcome [11]. Furthermore, they can be embedded into electronic Patient Care Records (ePCR), removing the labour involved in triage and allowing for more complex models to be integrated [12].

The application of non-ML triage algorithms has previously led to the majority of patients being identified as midacuity. The Emergency Severity Index (ESI) is one such example $[10,11]$. These triage systems can often have a clinical time-cost in their application [7]. In order for the benefits of triage algorithms to be actualised, the patient benefit at every acuity level has to be shortened. This means those with high acuity needs are treated quicker, those who are likely to be admitted are identified sooner and those with low acuity needs are discharged faster [10].

\section{Clinical role for the index test}

The index test under investigation in this systematic review is any triage model that is applied by a clinician at the point of entry in the ECS. There are three possible entry points for patients. The first is when a patient calls the emergency medical service and is triaged by the Emergency Operations Centre (EOC). The second entry point is a face-to-face assessment by a paramedic onscene. The third is on arrival to the Emergency Department (ED) [13]. A patient may enter at any of these points and also move through them all, being triaged multiple times. However the objective at each stage is the same: to stratify the acuity of an individual patient and allow the result to modify an ongoing care plan.

\section{Objectives}

The primary objective of this review is to assess the accuracy of machine learning methods in their application of triaging the acuity of patients presenting in the Emergency Care System (ECS).

\section{Methods}

This review followed the Preferred Reporting Items for Systematic Reviews and Meta-Analysis (PRISMA) statement. It is registered with PROSPERO (CRD42020168696).

\section{Eligibility criteria Population}

All patients presenting to the ECS who require a process of triage to discern the immediacy of care. The population cannot be differentiated by clinical severity or condition prior to the application of the triage tool. This is due to the index test under investigation being able to be applied to all incoming patients. The population can be differentiated by demographic variables such as age, as it is recognised, there is a difference in service need between younger and older populations [14-19].

\section{Intervention (index test)}

Machine learning algorithms that have been used to derive and internally validate a decision support tool. This includes commonly used methods such as logistic regression. However, for this review, the application of logistic regression must extend to making predictions in future data and not just uncovering patterns. The restriction to only derivation and internal validation studies is to ensure the method under investigation is clearly 
defined as opposed to an existing tool being externally validated in a subsequent population.

\section{Comparison (reference test)}

The reference test in this review is hierarchical. Preferably, there would be a decision support tool already used in the clinical setting identified in the paper as a comparator. In the absence of such, the study would include a clinician judgement. However, studies that have no comparator would also be accepted because derivation studies can often lack performance comparison with existing practice.

\section{Outcome}

For clarification, outcome has been divided into two parts. Prediction outcome and accuracy outcome.

\section{Prediction outcome}

To be included in this review, the outcome has to be a triage acuity outcome for emergency care. Each included study is aiming to make a prediction about how ill a patient is, or how urgent their care need is. Because the methods of how these predictions are developed is under investigation in this systematic review, the prediction outcome was allowed to be broadened in order to capture all relevant studies. This may be strictly a triage level (such as the Emergency Severity Index 5-level) or a surrogate outcome such as predicting the need for critical care or hospitalisation.

\section{Model performance}

For all the prediction models that have been included, their performance is described in terms of accuracy metrics reported in the final model performance. This includes discrimination (C-statistic), calibration (calibration plot, calibration slope, Hosmer-Lemeshow) and classification statistics (sensitivity, specificity, accuracy, positive predictive value (PPV), negative predictive value (NPV), likelihood ratio $+/-)$. Some studies have used synonyms such as 'precision' instead of PPV, or 'recall' instead of sensitivity. For clarity in this review, all terms have been aligned to classification statistics identified in Steyerberg et al. [20].

\section{Information sources}

On the 14th December 2019, the Medical Literature Analysis and Retrieval System Online (MEDLINE), the Cumulative Index to Nursing and Allied Health Literature (CINAHL), PubMed and the grey literature were searched. This included Google scholar and the IEEE arXiv.

\section{Search}

A search strategy was developed through iteration and piloting. It was adapted from key words identified in the research questions and can be found in the supplementary material. The search strategy was used for MEDLINE, CINAHL and PubMed. This can be found in the supplementary material.

The search strategy was for the last 10 years only. This is due to clinical contexts and computer capabilities being rapidly changing industries and thus older studies have a higher risk of being void or outdated. The search also encompassed only those studies presented in the English language. This is due to limited access to interpretation services. Any non-English language studies were excluded at the selection stage.

\section{Study selection}

Title screening was performed directly on source sites by JM and then exported to Endnote (version X9 for Windows) for abstract screening. This was subsequently fully second screened by JT. Then full text screening was performed by JM, with JT independently reviewing a random sample of $30 \%$ of the chosen included texts. Results were then compared with any disagreements being resolved by a third reviewer (SM). The data was selected from the studies retrieved during the searches using a visual schema transposed from the inclusion and exclusion criteria. This can be found in the supplementary material. There were four stages of selection based on the screening results of the studies. The first involved a population assessment, ensuring the study was set in the emergency care system and the patients are not differentiated clinically. The second stage involved intervention screening and ensuring the candidate variables were measured at triage (entry point). The third stage involved method screening, which in turn was subdivided into two sections, the first ensuring that machine learning was used to derive the model, and the second, ensuring that the methodological outcome was accuracy in prediction. The final stage involved outcome screening, ensuring that each selected study was setting out to riskstratify patients. There was co-author validation of the included articles.

\section{Data collection process}

Data was extracted using the Critical Appraisal and Data Extraction for Systematic Reviews of Prediction Modelling Studies (CHARMS) checklist [21]. This was completed in Microsoft Excel (2016) by JM. The total spreadsheet was reviewed by RJ. Any disagreements were mediated by a third reviewer (JT). Data extracted for each included study is provided in the supplementary material, as well as details regarding study quality assessment.

\section{Risk of bias and applicability}

Risk of bias and applicability was undertaken using the Prediction model Risk of Bias Assessment Tool (PROBAST) [22]. A template was accessed at http://www.probast.org/ wp-content/uploads/2020/02/PROBAST_20190515.pdf 
It was completed for each model by JM and then checked by RJ. Any disagreements were mediated by a third reviewer (JT).

\section{Diagnostic accuracy measures}

The principle diagnostic accuracy measures will be broadly covering three key areas. These are calibration, discrimination and classification of the final model within each study.

\section{Synthesis of results}

The included studies were too heterogeneous to undertake a robust meta-analysis; therefore, a narrative synthesis was performed. This centred on discrimination as the most reported summary statistic of model performance. Where derivation and internal validation results have been presented separately in a model, only the internally validated performance is included in this review and not the apparent performance.

The included models were sub-grouped by outcome, and further by method. Median and IQR was used to illustrate the spread of the C-statistics within each method. The analysis plan was informed by the Cochrane Handbook for Systematic Reviews of Diagnostic Test Accuracy [23].

\section{Results}

\section{Study selection}

All databases were searched on the 14th December 2019. There was a total of 712 studies identified from the database searching. This included 257 from MEDLINE, 298 from CINAHL and 150 from PubMed. Seven other sources from the grey literature were found. After title and abstract screening, 55 studies were taken through to eligibility screening. Thirty articles were excluded for the following reasons: 3 were external validation only, 6 were not machine learning, 2 were protocol only, 3 were studying the wrong population, 1 was a prognostic factor study, 13 had patients that were already triaged and 2 studies were not related to triage. This left a total of 25 studies included in this review. A PRISMA schematic diagram can be found below, and the PRISMA checklist can be found in the supplementary material [24]. Many studies investigated more than one machine learning technique, which meant that contained within the included studies was a total of 92 models to examine in this review (Fig. 1).

\section{Study characteristics}

The three most common methods were logistic regression (36 models), tree-based methods (23) and neural networks (20). Other models included support vector machines (6), Bayesian models (5), a K-nearest neighbour model and a unique artificial neuro-fuzzy inference system. Of the 92 models, there were only 13 that were set in the prehospital setting. The rest were set in the ED at the point of triage. The two main outcomes that were being predicted by the studies were admission to hospital (53 models) or critical care outcome (28 models). Less common outcomes that appeared in these studies were predicting existing triage structures ( 9 models), and the prediction of whether a patient would be discharged from ED (3 models). Table 1 below summarises the key features of the included studies.

There were 44 models derived in the USA, 18 in Korea, 14 in Australia, 5 in Spain, 4 in India, 2 in Malaysia, 2 in Israel and 1 in Taiwan, Scotland and the Netherlands. Eighty-four models were purely retrospective using existing registry or cohort data. Only 4 models included data collection that was prospective and there were 4 models that did not include whether the data source was retrospective or prospective. Sixty-three models were derived using data from multiple sites, whilst 25 models were developed using a single centre. Four models failed to publish this information.

\section{Risk of bias and applicability}

There was a significant amount of incomplete reporting within the results. Only four models reported any calibration, mainly using the Hosmer-Lemeshow statistic [27, 44, 48]. One reported the $p$ value of this, but not the statistic itself [27]. In terms of discrimination, there were 81 models that reported a concordance statistic (C -statistic), but of these, only 74 generated confidence intervals around this statistic. Only 47 models described classification statistics; however, these were incongruous between studies and only 1 study included the amount of true positive, true negative, false positive and false negative results. This makes it unfeasible to meta-analyse models which share the same population and outcome. A summary of the PROBAST assessment can be found in Fig. 2 and was adapted from Debray et al. [50]. When applying the PROBAST tool, there were only three studies which could be considered a low risk of bias [31,33,42]. This limits the benefit of grouping high vs low risk of bias studies. Most studies had low applicability concern, except for six studies $[26,30,38,41,46,49]$.

\section{Synthesis of results Hospitalisation outcome}

There was a total of 56 models which were predicting whether the patient was likely to be hospitalised as the outcome. Of these, 27 used logistic regression (two used the LASSO penalty term). Twelve studies used a neural network, 10 used a tree-based design, 3 Bayesian methods, 3 support vector machine models and one K-nearest neighbour. Only three models reported calibration in this outcome group [28, 48]. The most reported result was model discrimination using the $\mathrm{C}$-statistic (also known as the area under the ROC curve, or AUC). Whilst the heterogeneity 


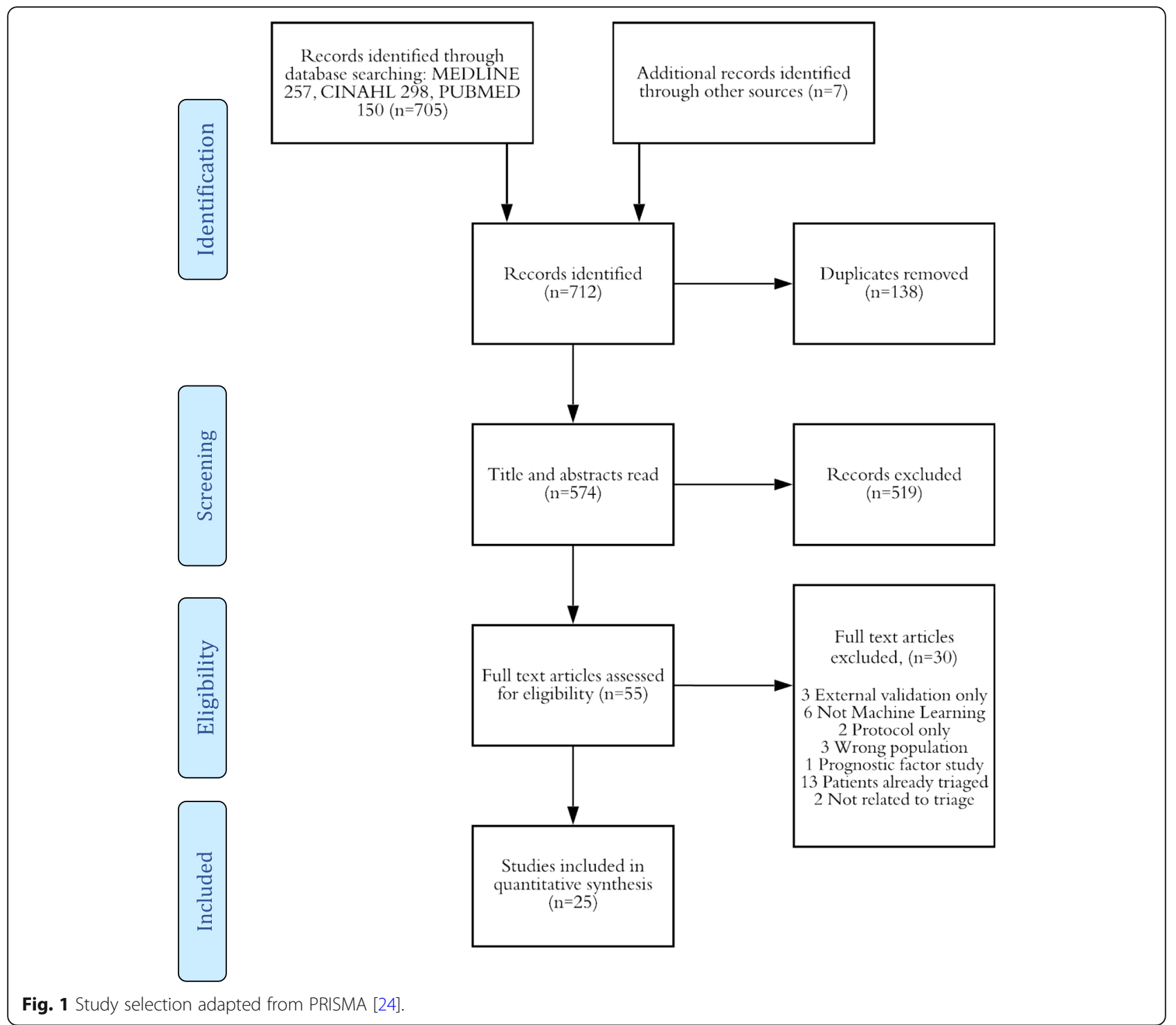

between models is too severe to undertake a meta-analysis, it was possible to cluster results by outcome and method. Figure 3 illustrates which machine learning methods were most able to differentiate between those with a positive outcome and those with a negative. The size of the data points is a normalised transformation of the sample size used to derive each model. Neural networks and treebased methods both had a median C-statistic of 0.81 with their interquartile ranges (IQR) being $0.80-0.84$ and 0.79 0.82 respectively. This compares to logistic regression which had a median C-statistic of 0.80 (IQR 0.74-0.83). The larger sample sizes generated smaller $\mathrm{C}$-statistics. The three support vector machine models did not report the Cstatistic. Classification was poorly reported with only 19 models publishing sensitivity and specificity, and only 10 of these also reporting confidence intervals. Twenty-one models reported accuracy, but only four of these had confidence intervals. Please refer to the CHARMS supplement for more details.

\section{Critical illness}

There were 28 models that used critical illness as an outcome measure. Eleven were logistic regression (one with LASSO penalty), 11 were tree-based and 6 were neural networks. There was an incongruency with the precise definition of critical illness, Table 2 highlights the differences within the definitions. Only one model in this group reported any calibration. They found that deep neural networks were the most discriminate with a C-statistic of 0.89 (95\% CI 0.88-0.89). This compared to logistic regression and random forest modelling which both had the same result of 0.87 (95\% CI 0.86-0.87).

The most common statistic was the C-statistic for discrimination. Figure 4 illustrates which methods were 
Table 1 Study characteristics

\begin{tabular}{|c|c|c|c|c|c|c|c|c|c|}
\hline Author & Year & Country & Population & Outcome & $\begin{array}{l}\text { Methods } \\
\text { used }\end{array}$ & Predictors & $\begin{array}{l}\text { Sample } \\
\text { size }\end{array}$ & EPV & Method of testing \\
\hline Azeez et al. [25] & 2014 & Malaysia & ED & Triage level & NN, ANFIS & 20 & 2223 & & $\begin{array}{l}\text { Random split sample } \\
(70: 30)\end{array}$ \\
\hline $\begin{array}{l}\text { Caicedo-Torres } \\
\text { et al. [26] }\end{array}$ & 2016 & Spain & ED & Discharge & LR, SVM, NN & 147 & 1205 & & $\begin{array}{l}\text { Random split sample } \\
(80: 20), 10-f C V\end{array}$ \\
\hline $\begin{array}{l}\text { Cameron et al. } \\
\text { [27] }\end{array}$ & 2015 & Scotland & ED & Hospitalisation & LR & 9 & 215231 & & $\begin{array}{l}\text { Random split sample } \\
(66: 33), \text { bootstrapping } \\
(10,000)\end{array}$ \\
\hline Dinh et al. [28] & 2016 & Australia & ED & Hospitalisation & LR & 10 & 860832 & 9470 & $\begin{array}{l}\text { Random split sample } \\
(50: 50)\end{array}$ \\
\hline Dugas et al. [29] & 2016 & USA & ED & Critical illness & LR & 9 & 97000000 & 525 & $\begin{array}{l}\text { Random split sample } \\
(90: 10), 10 f-C V\end{array}$ \\
\hline $\begin{array}{l}\text { Golmohammadi } \\
{[30]}\end{array}$ & 2016 & USA & ED & Hospitalisation & $L R, N N$ & 8 & 7266 & 460.25 & Split sample (70:30) \\
\hline Goto et al. [31] & 2019 & USA & ED & $\begin{array}{l}\text { Critical illness, } \\
\text { hospitalisation }\end{array}$ & $\begin{array}{l}\text { LR, LASSO, RF, } \\
\text { GBDT, DNN }\end{array}$ & 5 & 52037 & 32.60 & $\begin{array}{l}\text { Random split sample } \\
(70: 30)\end{array}$ \\
\hline Hong et al. [32] & 2018 & USA & ED & Hospitalisation & LR, GBDT, DNN & 972 & 560486 & 171.44 & $\begin{array}{l}\text { Random split sample } \\
(90: 10)\end{array}$ \\
\hline Kim, D et al. [33] & 2018 & Korea & Prehospital & Critical illness & $L R, R F, D N N$ & 5 & 460865 & 3583.60 & $10 f-C V$ \\
\hline Kim, S et al. [34] & 2014 & Australia & ED & Hospitalisation & LR & 8 & 100123 & 1074.86 & Apparent performance \\
\hline $\begin{array}{l}\text { Kwon et al. (1) } \\
\text { [35] }\end{array}$ & 2018 & Korea & ED & $\begin{array}{l}\text { Critical illness, } \\
\text { hospitalisation }\end{array}$ & DNN, RF & 7 & 10967518 & 133667.89 & $\begin{array}{l}\text { Split sample }(50: 50),+ \\
\text { external validation dataset }\end{array}$ \\
\hline $\begin{array}{l}\text { Kwon et al. (2) } \\
\text { [36] }\end{array}$ & 2019 & Korea & ED & $\begin{array}{l}\text { Critical illness, } \\
\text { hospitalisation }\end{array}$ & DNN, RF, LR & 8 & 2937078 & 14047.57 & Split sample (50:50) \\
\hline Levin et al. [37] & 2018 & USA & ED & $\begin{array}{l}\text { Critical illness, } \\
\text { hospitalisation }\end{array}$ & RF & 6 & 172726 & 56.74 & $\begin{array}{l}\text { Random split sample } \\
\text { (66:33), bootstrapping }\end{array}$ \\
\hline Li et al. [38] & 2009 & USA & Pre-hospital & Hospitalisation & $\begin{array}{l}\text { LR, NB, DT, } \\
\text { SVM }\end{array}$ & 6 & 2784 & & $10 f-C V$ \\
\hline Meisel et al. [39] & 2008 & USA & Pre-hospital & Hospitalisation & LR & 9 & 401 & & $\begin{array}{l}\text { Bootstrap resampling } \\
(1000)\end{array}$ \\
\hline $\begin{array}{l}\text { Newgard et al. } \\
\text { [40] }\end{array}$ & 2013 & USA & Prehospital & Critical illness & CART & 40 & 89261 & & Cross-validation \\
\hline Olivia et al. [41] & 2018 & India & ED & Triage level & $\begin{array}{l}\text { DT, SVM, NN, } \\
\text { NB }\end{array}$ & 8 & & & $10 f-C V$ \\
\hline Raita et al. [42] & 2019 & USA & ED & $\begin{array}{l}\text { Critical illness, } \\
\text { hospitalisation }\end{array}$ & $\begin{array}{l}\text { LR, LASSO, RF, } \\
\text { GBDT, DNN }\end{array}$ & 6 & 135470 & 107 & $\begin{array}{l}\text { Random split sample } \\
(70: 30)\end{array}$ \\
\hline $\begin{array}{l}\text { Rendell et al. } \\
\text { [43] }\end{array}$ & 2019 & Australia & ED & Hospitalisation & $\begin{array}{l}\text { B, DT, LR, NN, } \\
\text { NB, KNN }\end{array}$ & 11 & 1721294 & 5521 & $10 \mathrm{f}-\mathrm{CV}$ \\
\hline $\begin{array}{l}\text { Seymour et al. } \\
\text { [44] }\end{array}$ & 2010 & USA & Prehospital & Critical illness & LR & 12 & 144913 & 156 & $\begin{array}{l}\text { Random split sample } \\
(60: 40)\end{array}$ \\
\hline $\begin{array}{l}\text { van Rein et al. } \\
\text { [45] }\end{array}$ & 2019 & Netherlands & Prehospital & Critical illness & LR & 48 & 6859 & 3.4375 & $\begin{array}{l}\text { Separate external } \\
\text { validation }\end{array}$ \\
\hline Wang et al. [46] & 2013 & Taiwan & $\mathrm{ED}$ & Triage level & SVM & 6 & 3000 & & $10 \mathrm{f}-\mathrm{CV}$ \\
\hline Zhang et al. [47] & 2017 & USA & $\mathrm{ED}$ & Hospitalisation & $L R, N N$ & 25 & 47200 & 91.8 & $10 f-C V$ \\
\hline Zlotnik et al. [48] & 2016 & Spain & ED & Hospitalisation & NN & 9 & 153970 & 614.5 & $10 f-C V$ \\
\hline Zmiri et al. [49] & 2012 & Israel & ED & Triage level & $\mathrm{NB}, \mathrm{C} 4.5$ & 4 & 402 & & $10 f-C V$ \\
\hline
\end{tabular}

ANFIS Adaptive Neuro-Fuzzy Inference System, B Bayesian Network, CART Classification and Regression Tree, DT Decision Tree, DNN Deep Neural Network, EPV Events Per Variable, GBDT Gradient Boosted Decision Tree, KNN K-Nearest Neighbours, LR logistic regression, LASSO Least Absolute Shrinkage and Selection Operator, NB Naïve Bayes, NN Neural Network, RF Random Forest, SVM Support Vector Machine

most discriminative at predicting a critical care outcome. As above, the sample size is represented by the size of the data point. Neural networks had a median of 0.89 (IQR 0.87-0.90) tree based had a median of 0.85 (IQR
0.84-0.88) and logistic regression had a median of 0.83 (IQR 0.80-0.85).

There were only 10 models from two studies that included classification metrics such as sensitivity and 

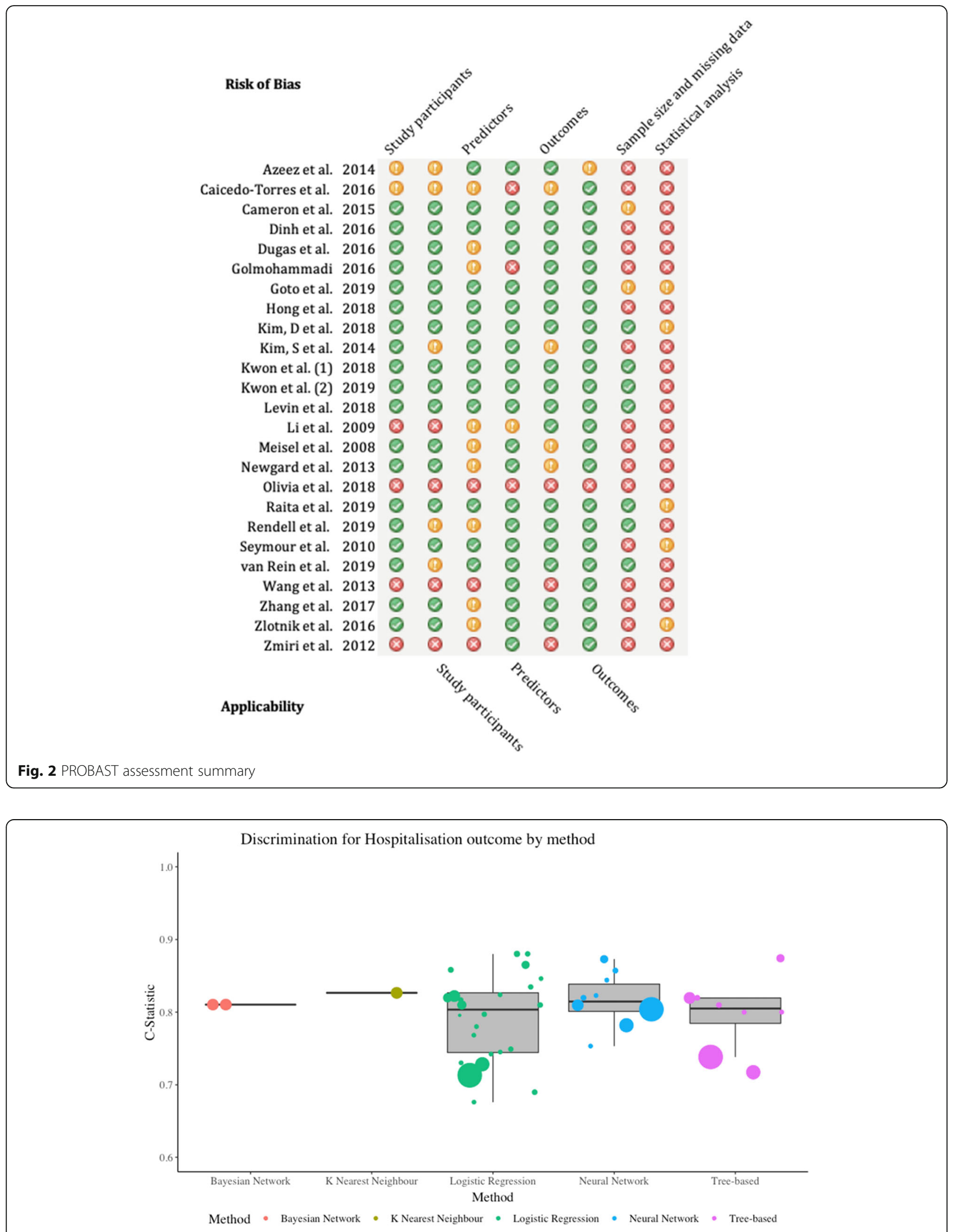

Fig. 3 Discrimination for hospitalisation outcome by method 
Table 2 Critical care outcome definitions between studies

\begin{tabular}{|c|c|c|c|c|c|c|c|c|}
\hline Study & Direct ICU & Death & Direct theatre & Direct $\mathrm{pPCl}$ & Severe sepsis & Mechanical intervention & ISS $>15$ & ISS $>16$ \\
\hline Dugas et al. & $\checkmark$ & $\checkmark$ & $\checkmark$ & $\checkmark$ & & & & \\
\hline Goto et al. & $\checkmark$ & $\checkmark$ & & & & & & \\
\hline Kim D et al. & & $\checkmark$ & & & & & & \\
\hline Kwon et al. & $\checkmark$ & $\checkmark$ & & & & & & \\
\hline Kwon et al. (2) & $\checkmark$ & & & & & & & \\
\hline Levin et al. & $\checkmark$ & $\checkmark$ & & & & & & \\
\hline Newgard et al. & & & & & & & & $\checkmark$ \\
\hline Raita et al. & $\checkmark$ & $\checkmark$ & & & & & & \\
\hline Seymour et al. & & $\checkmark$ & & & $\checkmark$ & $\checkmark$ & & \\
\hline van Rein et al. & & & & & & & $\checkmark$ & \\
\hline
\end{tabular}

ICU Intensive Care Unit, $\mathrm{pPCI}$ primary Percutaneous Coronary Intervention, ISS injury severity score

specificity with their associated confidence intervals [31, 42]. This makes comparison limited.

\section{Discharge outcome}

Three models from a single study used discharge related outcome measures [26]. The study focussed on predicting patients that would be discharged from the ED, and diverting them to a fast track service. They used logistic regression, support vector machines and neural networks for comparison. They did not report discrimination and only reported limited classification statistics [26]. They found that the neural network had the most precise estimates with a PPV (0.85) compared to the support vector machine and logistic regression (0.83 and 0.82). However, when examining the reported F1 score (PPV* sensitivity/PPV + sensitivity), logistic regression reported the most accurate estimate with an F1 score of 0.85, compared to the support vector machine (0.82) and the neural network (0.82).

\section{Triage level outcome}

Three studies that used machine learning to stratify patients into existing triage tools, all of which had a high risk of bias [25, 46, 49]. One focused on the Objective Primary Triage Scale (OPTS) in Malaysia [25]. This is a three tiered triage scale of emergent, urgent and non-urgent. They used neural networks and an artificial neuro-fuzzy inference system (ANFIS) to make predictions. There was no model calibration performed and the C-statistic did not have any confidence intervals. They did report accuracy and PPV for both methods and found the neural network had an accuracy of 0.84 (PPV 0.87) which was better performing than the ANFIS method (accuracy 0.6, PPV 0.61) [25]. Two studies used a local four level triage scale [46, 49]. One used Support Vector Machines with a Principle Component Analysis and a back propagated neural network, reporting an accuracy of 1.0 and 0.97 respectively [46]. The results in this study are likely to be biassed. The

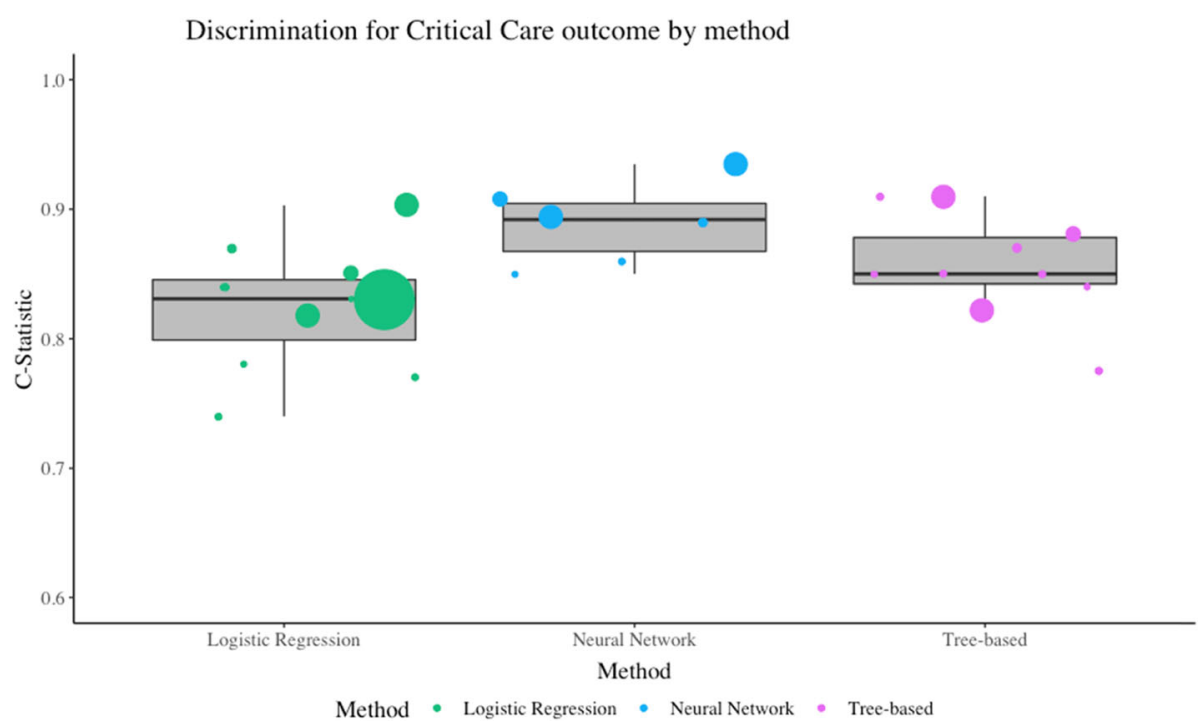

Fig. 4 Discrimination for critical care outcome by method 
other study which examined a four-tiered triage scale used a naïve Bayes and a C4.5 tree-based classifier [49]. They only reported accuracy; however, they found that when they simplified the scale to be two grades, both models had higher prediction (average accuracy 71.37) than when it was four grades (52.94).

\section{Discussion}

\section{Summary of included studies}

In the last 10 years, there has been an increase in the number of prediction models that have utilised already existing methods in statistics and computer science. This may be due to the widespread availability of data worldwide. This systematic review identified 25 studies which aimed to derive a risk prediction model for triaging the acuity of undifferentiated patients in the emergency care system. The most common method was logistic regression with 36 models, but this was followed closely by both treebased methods and neural networks. Most studies used hospital admission as an outcome for prediction. The objective of this review was to assess the accuracy of different machine learning methods. This was challenging due to differences in reporting how models were developed and evaluated. Furthermore, the reporting of the majority of models did not give enough information on model development, validation and performance which makes a critical appraisal difficult and a meta-analysis of accuracy stratified by the method almost impossible.

There have been common pitfalls amongst the included studies which will be discussed including the reference standard, the handling of candidate variables, and the analysis of performance.

\section{The reference standard}

In evaluating the performance of a diagnostic model, it is important to compare the index test (the new model) with a 'gold standard', known as the reference standard. In practice, this could be subjective such as a clinician making a decision or deciding a triage level. Alternatively, it could be an objective standard such as an ICD-10 classification of disease, mortality or a clearly defined event [51].

Most studies that are determining the cross-sectional acuity of any given patient in emergency care have subjective reference standards. To illustrate, the Emergency Severity Index (ESI) 5-level triage is almost exclusively subjective and depends on the clinician undertaking the triage. A limitation of using this as a reference standard is inter-rater reliability can widely vary. A meta-analysis has shown that the inter-rater reliability of the ESI had an unweighted kappa of 0.786 (95\% CI 0.745-0.821) [52]. Using subjective reference standards could lead to inherent problems maintaining the accuracy when transporting the model.
In contrast, Liu et al. undertook a study predicting cardiac arrest within $72 \mathrm{~h}$ of ED attendance [53]. A cardiac arrest is an empirical outcome measure and can be defined as "the abrupt loss of heart function in a person who may or may not have been diagnosed with heart disease" [54]. Liu prospectively collected data on 1386 participants and recorded whether or not they had a cardiac arrest within $72 \mathrm{~h}$. In this example, the reference standard is a clearly defined outcome, which is not open for interpretation or subjectivity, and thus would provide a reliable benchmark to compare a derived model.

\section{Handling of candidate variables}

Prior to developing a diagnostic model, it is important to consider which variables in the data are candidates for the final model. These candidate variables can be identified not only through subject knowledge or literature searching but also through statistical methods of examining the distribution or weighting [20]. A common problem with the included studies was how they reported the identification of candidate variables. Fifteen of the included studies provided a clear rationale, with data available at triage being the most common reason. Two studies used all the variables in the dataset, and eight studies provided no rationale at all.

It is also important to rationalise why there is a need to transform continuous variables given that it can be statistically inappropriate when developing prognostic models and leads to a significant loss of information [55]. Only 6 studies kept variables in their original format, whilst the remaining studies either categorised the variables (such as age) or did not describe the variables in a level of detail that an assessment could be made. Furthermore, no study elaborated on the linearity of the continuous variables and reported how they would model non-linear relationships (such as using fractional polynomials or restricted cubic splines) [56].

One of the benefits of using machine learning is the ability of performing feature selection during analysis [1]. The methods of undertaking feature selection can vary according to method, but the principle is beneficial to creating a simple model that can be embedded into practice. Methods such as deep neural networks can allow for fitting complex non-linear relationships through their architecture. The more hidden layers, the more complex the relationships. Univariable screening is not recommended as it does not account for any important collinearities between other candidate variables [57]. Despite this, it was used in 5 of the included studies.

\section{Reporting}

The concordance statistic (C-statistic) was the most commonly reported and appeared in 81 out of 97 models. The $\mathrm{C}$-statistic evaluates how discriminative a model is. For example, if a pair of subjects were selected at random (one with the outcome and one without), how often would the 
model classify both subjects correctly [58]. There were no significant differences in discrimination between methods, and all reported a range of $\mathrm{C}$-statistics that performed well (above 0.7). However, reporting how discriminative a model is does not provide a full picture and the performance of the model should account for calibration. This is an assessment of accuracy or more specifically, how well the predictions matched the observed outcomes in the data [56]. If studies only report discrimination, then it does not help troubleshoot poor performance in a transported model. This is when the model is adopted in a new setting, such as a new hospital, or new country. Only five models reported any calibration, and two of these used the Hosmer-Lemeshow statistic [44, 48]. This is prone to poor interpretability and can be sensitive to sample size and grouping [56]. With machine learning methods, miscalibration can be adjusted when transporting a model to a different setting. Further ways to present accuracy are classification statistics. These include accuracy, sensitivity, specificity, positive predictive value (PPV), negative predictive value (NPV), and likelihood ratios.

No studies reported classification statistics in full. If they had published the true positive, false positive, true negative and false negative results for their model performance, a meta-analysis could have been performed [23].

Nearly all the studies had the potential of a high risk of bias due to the results being incomplete. More information is needed in order to make a robust judgement. The PROBAST statement recommends transparency in reporting and the transparent reporting of a multivariable prediction model for individual prognosis or diagnosis (TRIPOD) gives clear guidance on how to achieve this. Even though machine learning can be perceived as 'black box', this axiom is not entirely true. For example, DNN can obtain a matrix of parameter values and this can then be subsequently transformed into the ranking of variable importance. The reporting of model performance can still be generated $[59,60]$.

\section{Limitations in this review}

This review identified and appraised all available literature; however, it did not directly contact authors for original data or further statistics. As such, the level of missing data in reporting which prevented the generation of a summary statistic remained throughout. This also had an impact on the risk of bias assessment. The Excerpta Medica database (EMBASE) was not used in this review as it was deemed too similar to MEDLINE.

\section{Conclusion}

This systematic review has found that machine learning methods such as neural networks, tree-based, and logistic regression designs appear equal at triaging undifferentiated patients. However, the inconsistency and absence of information has significant implications on the risk of bias in all studies. Therefore no definitive answer can be drawn about the most accurate method. Future studies need to conform to reporting guidelines to ensure transparency and integrity of the models.

\section{Supplementary information}

Supplementary information accompanies this paper at https://doi.org/10. 1186/s41512-020-00084-1.

\section{Additional file 1:.}

\section{Abbreviations}

ANFIS: Adaptive Neuro-Fuzzy Inference System; AUC: Area under curve; B: Bayesian network; CART: Classification and regression trees; CHAR MS: Critical Appraisal and Data Extraction for Systematic Reviews of Prediction Modelling Studies; CINAHL: The Cumulative Index to Nursing and Allied Health Literature; CT: Computerised tomography; DNN: Deep neural network; DT: Decision tree; ECS: Emergency Care System; ED: Emergency Department; EOC: Emergency Operations Centre; EPCR: Electronic patient care record; EPV: Events per variable; ESI: Emergency severity index; GBDT: Gradient boosted decision tree; GRACE: Global Registry of Acute Coronary Event; ICD-10: International Classification of Disease-10; IQR: Interquartile range; KNN: K-nearest neighbours; LR: Logistic regression; MEDL INE: Medical Literature Analysis and Retrieval System; ML: Machine learning; NIHR: National Institute for Health Research; NN: Neural network; NPV: Negative predictive value; OPTS: Objective Primary Triage Scale; PPV: Positive predictive value; PROBAST: Prediction model Risk Of Bias Assessment Tool; PROSPERO: The International Prospective Register of Systematic Reviews; RF: Random Forest; ROC: Receiver operating characteristic; SVM: Support vector machine; TIMI: Thrombolysis in Myocardial Infarction; TRIPOD: Transparent Reporting of a multivariable prediction model for Individual Prognosis Or Diagnosis

\section{Acknowledgements}

Not applicable

\section{Authors' contributions}

JM developed the search strategy, ran the search, did initial screening, analysed the data and was the primary author of the manuscript. JT second screened the data and reviewed eligible studies, also steered the clinical perspective of the project. RJ co-developed the statistical analysis plan and reviewed the analysis. JW shaped the clinical importance of the review and checked the clinical context of the included studies. SM provided oversight for the review, steered the search strategy to ensure clinical context was maintained. The authors read and approved the final manuscript.

\section{Authors' information}

JM is a paramedic and currently leading a project called the Safety INdEx of Prehospital On Scene Triage (SINEPOST) which is a prediction study aiming to derive and internally validate a model which can help paramedics make transport decisions whilst still with the patient. For more information on this project, and the lead author visit: https://www.sheffield.ac.uk/scharr/people/ pgr-students/jamie-miles

\section{Funding}

This study was funded by Health Education England and the National Institute of Health Research. The funders have not inputted into the collection, analysis or interpretation of data in writing this manuscript. This report is independent research supported by Health Education England and the National Institute of Health Research (HEE/NIHR ICA Programme Clinical Doctoral Research Fellowship, Mr. Jamie Miles, ICA-CDRF-2018-04ST2-044). The views expressed in this publication are those of the author(s) and not necessarily those of the NHS, the National Institute for Health Research or the Department of Health and Social Care. 


\section{Availability of data and materials}

The datasets used and/or analysed during the current study are available from the corresponding author on reasonable request.

\section{Ethics approval and consent to participate}

Not applicable

\section{Consent for publication}

Not applicable

\section{Competing interests}

The authors declare that they have no competing interests

\section{Author details}

${ }^{1}$ Yorkshire Ambulance Service, Brindley Way, Wakefield WF2 OXQ, UK. ${ }^{2}$ School of Health and Related Research, 3rd Floor, Regent Court (ScHARR), 30 Regent Street, Sheffield S1 4DA, UK. ${ }^{3}$ University of Herfordshire, Hatfield, Herfordshire, UK.

Received: 30 July 2020 Accepted: 11 September 2020 Published online: 02 October 2020

\section{References}

1. Murphy KP. Machine learning: a probabilistic perspective. London: the MIT press; 2012.

2. Bektas F, Eken C, Soyuncu S, Kilicaslan I, Cete Y. Artificial neural network in predicting craniocervical junction injury: an alternative approach to trauma patients. Eur J Emerg Med. 2008 Dec;15(6):318-23.

3. Walsh P, Cunningham P, Rothenberg SJ, O'Doherty S, Hoey H, Healy R. An artificial neural network ensemble to predict disposition and length of stay in children presenting with bronchiolitis. Eur J Emerg Med. 2004;11(5):259_ 64.

4. Molaei S, Korley FK, Soroushmehr SMR, Falk H, Sair H, Ward K, et al. A machine learning based approach for identifying traumatic brain injury patients for whom a head CT scan can be avoided. In: Proceedings of the Annual International Conference of the IEEE Engineering in Medicine and Biology Society, EMBS. Institute of Electrical and Electronics Engineers Inc.; 2016. p. 2258-61.

5. Vanhouten JP, Starmer JM, Lorenzi NM, Maron DJ, Lasko TA. Machine learning for risk prediction of acute coronary syndrome.

6. Harrison RF, Kennedy RL. Artificial neural network models for prediction of acute coronary syndromes using clinical data from the time of presentation. Ann Emerg Med. 2005 Nov 1;46(5):431-9.

7. Weber EJ. Triage: Making the simple complex? Emerg Med J. 2018;36(2):645.

8. O'Keeffe C, Mason S, Jacques R, Nicholl J. Characterising non-urgent users of the emergency department (ED): a retrospective analysis of routine ED data. PLoS One. 2018;13(2):1-14.

9. Stewart J, Sprivulis P, Dwivedi G. Artificial intelligence and machine learning in emergency medicine. Emerg Med Australas [Internet]. 2018 Dec;30(6): 870-4. Available from: http://doi.wiley.com/10.1111/1742-6723.13145.

10. Berlyand Y, Raja AS, Dorner SC, Prabhakar AM, Sonis JD, Gottumukkala R V.. et al. How artificial intelligence could transform emergency department operations. Am J Emerg Med [Internet]. 2018 Aug;36(8):1515-7. Available from: https://linkinghub.elsevier.com/retrieve/pii/S0735675718300184.

11. Grant K, McParland A. Applications of artificial intelligence in emergency medicine. Univ Toronto Med J. 2019;96(1):37-9.

12. Liu N, Zhang Z, Wah Ho AF, Ong MEH. Artificial intelligence in emergency medicine. J Emerg Crit Care Med. 2018;2(4):82-82

13. Aacharya RP, Gastmans C, Denier Y. Emergency department triage: an ethical analysis. BMC Emerg Med. 2011 Oct 7;11:16

14. Brousseau DC, Hoffmann RG, Nattinger AB, Flores G, Zhang Y, Gorelick M. Quality of primary care and subsequent pediatric emergency department utilization. Pediatrics. 2007 Jun 1;119(6):1131-8.

15. Simpson R, Croft S, O'Keeffe C, Jacques R, Stone T, Ahmed N, et al. Exploring the characteristics, acuity and management of adult ED patients at nighttime. Emerg Med J. 2019 Sep 1;36(9):554-7.

16. McCusker J, Karp I, Cardin S, Durand P, Morin J. Determinants of emergency department visits by older adults: a systematic review. Acad Emerg Med [Internet]. 2003 Dec 1 [cited 2020 Mar 6];10(12):1362-70. Available from: http://doi.wiley.com/10.1197/S1069-6563(03)00539-6.
17. Latham LP, Ackroyd-Stolarz S. Emergency department utilization by older adults: a descriptive study. Can Geriatr J. 2014 Dec 1;17(4):118-25.

18. Lehmann CU, Barr J, Kelly PJ. Emergency department utilization by adolescents. J Adolesc Heal. 1994;15(6):485-90.

19. Ziv A, Boulet JR, Slap GB. Emergency department utilization by adolescents in the United States. Pediatrics. 1998 Jun 1:101(6):987-94.

20. Steyerberg EW. Clinical prediction models: a practical approach to development, validation, and updating [Internet]. New York, NY: Springer New York; 2009. (Statistics for Biology and Health). Available from: http:// link.springer.com/10.1007/978-0-387-77244-8.

21. Moons KGM, de Groot JAH, Bouwmeester W, Vergouwe Y, Mallett S, Altman DG, et al. Critical appraisal and data extraction for systematic reviews of prediction modelling studies: the CHARMS checklist. PLoS Med [Internet]. 2014 Oct 14 [cited 2020 Mar 1];11(10):e1001744. Available from: https://dx. plos.org/10.1371/journal.pmed.1001744.

22. Wolff RF, Moons KGM, Riley RD, Whiting PF, Westwood M, Collins GS, et al. PROBAST: a tool to assess the risk of bias and applicability of prediction model studies. Ann Intern Med. 2019 Jan 1;170(1):51-8.

23. Macaskill P, Gatsonis C, Deeks J, Harbord R, Takwoingi Y. Analysing and presenting results. In: The Cochrane collaboration, editor. Cochrane Handbook for Systematic Reviews of Diagnostic Test Accuracy [Internet]. Version 1. 2010. Available from: http://srdta.cochrane.org/.

24. Moher D, Liberati A, Tetzlaff J, Altman DG. Preferred reporting items for systematic reviews and meta-analyses: the PRISMA statement. PLoS Med [Internet]. 2009 Jul 21 [cited 2020 Mar 6];6(7):e1000097. Available from: https://dx.plos.org/10.1371/journal.pmed.1000097.

25. Azeez D, Ali MAM, Gan KB, Saiboon I. Comparison of adaptive neuro-fuzzy inference system and artificial neutral networks model to categorize patients in the emergency department. Springerplus. 2013;2(1):1-10.

26. Caicedo-Torres W, Hernando Pinzon G. A machine learning model for triage in lean paediatric emergency departments. Montes y Gómez M, Escalante HJ, Segura A, Murillo J de D, editors. 2016;10022(November 2016):259-70. Available from: http://link.springer.com/10.1007/978-3-319-47955-2.

27. Cameron A, Rodgers K, Ireland A, Jamdar R, McKay GA. A simple tool to predict admission at the time of triage. Emerg Med J [Internet]. 2015;32(3): 174-9. Available from: http://ovidsp.ovid.com/ovidweb.cgi?T=JS\&PAGE= reference\&D=med11\&NEWS=N\&AN=24421344.

28. Dinh MM, Russell SB, Bein KJ, Rogers K, Muscatello D, Paoloni R, et al. The Sydney Triage to Admission Risk Tool (START) to predict emergency department disposition: a derivation and internal validation study using retrospective state-wide data from New South Wales, Australia. BMC Emerg Med [Internet]. 2016;16(1):1-7 Available from: http://ovidsp.ovid.com/ ovidweb.cgi?T=JS\&PAGE=reference\&D=med12\&NEWS=N\&AN=27912757.

29. Dugas AF, Kirsch TD, Toerper M, Korley F, Yenokyan G, France D, et al. An electronic emergency triage system to improve patient distribution by critical outcomes. J Emerg Med. 2016;50(6):910-8.

30. Golmohammadi D. Predicting hospital admissions to reduce emergency department boarding. Int J Prod Econ. 2016;182(September):535-44.

31. Goto T, Camargo CAJ, Faridi MK, Freishtat RJ, Hasegawa K. Machine learning-based prediction of clinical outcomes for children during emergency department triage. JAMA Netw open [Internet]. 2019;2(1): e186937. Available from: http://ovidsp.ovid.com/ovidweb.cgi?T=JS\&PAGE= reference\&D=prem\&NEWS=N\&AN=30646206.

32. Hong WS, Haimovich AD, Taylor RA. Predicting hospital admission at emergency department triage using machine learning. PLoS One [Internet]. 2018;13(7):1-13 Available from: http://ovidsp.ovid.com/ovidweb.cgi?T= JS\&PAGE $=$ reference $\& D=$ medl $\& N E W S=N \& A N=30028888$.

33. Kim D, You S, So S, Lee J, Yook S, Jang DP, et al. A data-driven artificial intelligence model for remote triage in the prehospital environment. PLoS One. 2018;13(10):1-14

34. Kim SW, Li JY, Hakendorf P, Teubner DJJO, Ben-Tovim DI, Thompson CH. Predicting admission of patients by their presentation to the emergency department. EMA - Emerg Med Australas. 2014 Aug;26(4):361-7.

35. Kwon Jmyoung, Lee YY, Lee YY, Lee S, Park H, Park J. Validation of deeplearning-based triage and acuity score using a large national dataset. PLoS One [Internet]. 2018;13(10):1-10. Available from: https://doi.org/10.1371/ journal.pone.0205836.

36. Kwon J, Jeon K-H, Lee M, Kim K-H, Park J, Oh B-H. Deep learning algorithm to predict need for critical care in pediatric emergency departments. Pediatr Emerg Care [Internet]. 2019 Jul;1. Available from: http://insights.ovid.com/ crossref?an=00006565-900000000-98117. 
37. Levin S, Toerper M, Hamrock E, Hinson JS, Barnes S, Gardner H, et al. Machine-learning-based electronic triage more accurately differentiates patients with respect to clinical outcomes compared with the emergency severity index. Ann Emerg Med. 2018;71(5):565-574.e2.

38. Li J, Guo L, Handly N. Hospital admission prediction using pre-hospital variables. 2009 IEEE Int Conf Bioinforma Biomed BIBM 2009. 2009:283-286.

39. Meisel ZF, Pollack CV, Mechem CC, Pines JM. Derivation and internal validation of a rule to predict hospital admission in prehospital patients. Prehospital Emerg Care. 2008;12(3):314-9.

40. Newgard CD, Hsia RY, Mann NC, Schmidt T, Sahni R, Bulger EM, et al. The trade-offs in field trauma triage. J Trauma Acute Care Surg [Internet]. 2013; 74(5):1298-306 Available from: http://insights.ovid.com/crossref?an=015 86154-201305000-00017.

41. Olivia D, Nayak A, Balachandra M. Machine learning based electronic triage for emergency department. In 2018. p. 215-21. Available from: http://link. springer.com/10.1007/978-981-13-2907-4_19.

42. Raita Y, Goto T, Faridi MK, Brown DFM, Camargo CA, Hasegawa K. Emergency department triage prediction of clinical outcomes using machine learning models. Crit Care [Internet]. 2019 22;23(1):64. Available from: https:/ccforum. biomedcentral.com/articles/10.1186/s13054-019-2351-7.

43. Rendell K, Koprinska I, Kyme A, Ebker-White AA, Dinh MM. The Sydney Triage to Admission Risk Tool (START2) using machine learning techniques to support disposition decision-making. EMA - Emerg Med Australas. 2019; 31(3):429-35.

44. Seymour CW, Kahn JM, Cooke CR, Watkins TR, Rea TD. During out-ofhospital emergency care. 2010;304(7):747-54.

45. van Rein EAJ, van der Sluijs R, Voskens FJ, Lansink KWW, Houwert RM, Lichtveld RA, et al. Development and Validation of a Prediction Model for Prehospital Triage of Trauma Patients. JAMA Surg [Internet]. 2019;154(5): 421-9 Available from: http://search.ebscohost.com/login.aspx?direct= true \&db=cin20\&AN=136501962\&site=ehost-live.

46. Wang S-T. Construct an optimal triage prediction model: a case study of the emergency department of a teaching hospital in Taiwan. J Med Syst [Internet]. 2013t 29;37(5):9968. Available from: http://link.springer.com/10.1 007/s10916-013-9968-X.

47. Zhang X, Kim J, Patzer RE, Pitts SR, Patzer A, Schrager JD. Prediction of emergency department hospital admission based on natural language processing and neural networks. Methods Inf Med [Internet]. 2017:56(05): 377-89 Available from: http://www.thieme-connect.de/DOI/DOI?10.3414/ ME17-01-0024

48. Zlotnik A, Alfaro MC, Pérez MCP, Gallardo-Antolín A, Martínez JMM. Building a decision support system for inpatient admission prediction with the Manchester triage system and administrative check-in variables. CIN Comput Informatics, Nurs [Internet]. 2016 May;34(5):224-30. Available from: http://content.wkhealth.com/linkback/openurl?sid=WKPTLP: landingpage\&an=00024665-201605000-00006.

49. Zmiri D, Shahar Y, Taieb-Maimon M. Classification of patients by severity grades during triage in the emergency department using data mining methods. J Eval Clin Pract. 2012;18(2):378-88 Available from: http://doi.wiley. com/10.1111/j.1365-2753.2010.01592.x.

50. Debray TPA, Damen JAAG, Snell KIE, Ensor J, Hooft L, Reitsma JB, et al. A guide to systematic review and meta-analysis of prediction model performance. BMJ. 2017;356.

51. Takwoingi Y, Quinn TJ. Review of diagnostic test accuracy (DTA) studies in older people. Age Ageing. 2018;47(3):349-55.

52. Mirhaghi A, Heydari A, Mazlom R, Hasanzadeh F. Reliability of the emergency severity index: meta-analysis. Sultan Qaboos Univ Med J. 2015; 15(1):e71-7.

53. Liu N, Lin Z, Cao J, Koh Z, Zhang T, Bin HG, et al. An intelligent scoring system and its application to cardiac arrest prediction. IEEE Trans Inf Technol Biomed. 2012;16(6):1324-31.

54. American Heart Association. Cardiac arrest [Internet]. 2020 [cited 2020 Jun 2]. Available from: https://www.heart.org/en/health-topics/cardiac-arrest\#: text=About Cardiac Arrest,the wake of other symptoms.

55. Collins GS, Ogundimu EO, Cook JA, Le Manach Y, Altman DG. Quantifying the impact of different approaches for handling continuous predictors on the performance of a prognostic model. 2016;

56. Riley RD, van der Windt D, Croft P, Moons KGM, editors. Prognosis research in health care [Internet]. Oxford University Press; 2019. Available from: http://www.oxfordmedicine.com/view/10.1093/med/9780198796619.001. 0001/med-9780198796619.
57. Sun G-W, Shook TL, Kay GL. Inappropriate use of bivariable analysis to screen risk factors for use in multivariable analysis. Vol. 49, J Clin Epidemiol. 1996.

58. Caetano SJ, Sonpavde G, Pond GR. C-statistic: a brief explanation of its construction, interpretation and limitations. Eur J Cancer. 2018;90:130-2.

59. Moons KGM, Altman DG, Reitsma JB, loannidis JPA, Macaskill P, Steyerberg EW, et al. Transparent reporting of a multivariable prediction model for individual prognosis or diagnosis (TRIPOD): explanation and elaboration. Ann Intern Med. 2015 Jan 6;162(1):W1-73.

60. Moons KGM, Wolff RF, Riley RD, Penny „, Whiting F, Westwood M, et al. PROBAST: a tool to assess risk of bias and applicability of prediction model studies: Explanation and Elaboration Annals of Internal Medicine RESEARCH AND REPORTING METHODS. Ann Intern Med [Internet]. 2019 [cited 2020 Mar 8];170:1-33. Available from: www.probast.org.

\section{Publisher's Note}

Springer Nature remains neutral with regard to jurisdictional claims in published maps and institutional affiliations.

\section{Ready to submit your research? Choose BMC and benefit from:}

- fast, convenient online submission

- thorough peer review by experienced researchers in your field

- rapid publication on acceptance

- support for research data, including large and complex data types

- gold Open Access which fosters wider collaboration and increased citations

- maximum visibility for your research: over $100 \mathrm{M}$ website views per year

At BMC, research is always in progress.

Learn more biomedcentral.com/submissions 